\title{
Perception and Practice of Malaria Prophylaxis in Pregnancy among Health care Providers in Ibadan
}

\author{
Onyeaso N.C, Fawole A.O
}

\begin{abstract}
The study assessed knowledge and practice of health care providers on current concepts on malaria prophylaxis in pregnancy. 497 randomly selected respondents at the three levels of care in two local governments in Ibadan, South western Nigeria were interviewed using a self-administered questionnaire. Respondents were selected from 45 health facilities: 48 (9.7\%) community health extension workers (CHEWS), 139 (28.9\%) auxiliary nurses, 220 (44.3\%) formally trained nurses and $90(18.1 \%)$ medical doctors. Only $57(11.5 \%)$ respondents were knowledgeable about current WHO strategies for malaria prevention in pregnancy. Three hundred and eighty six respondents $(77.7 \%)$ were aware of intermittent preventive treatment (IPT). Awareness about IPT was highest among CHEWS (95.8\%). Pyrimethamine was prescribed mainly by healthcare providers in the secondary $(60.6 \%)$ and primary $(60.3 \%)$ levels of care $\left(\mathrm{X}^{2}=11.54, \mathrm{p}<0.01\right)$. Chloroquine was prescribed by $42.5 \%$ of respondents. Sulfadoxine-pyrimethamine was significantly more commonly prescribed by primary health care providers than in other levels of care $\left(\mathrm{X}^{2}=15.07, \mathrm{p}<0.01\right)$. Prescription for insecticide treated nets was high. Respondents' practice of anti-malarial chemoprophylaxis was influenced by the cadre of the health care provider and level of practice. There are several knowledge gaps on current malaria prevention strategies in pregnancy among healthcare providers. Multiple strategies are required to improve health care workers' knowledge and practice of malaria prevention during pregnancy. (Afr J Reprod Health 2007; 11[2]:60-69).
\end{abstract}

\section{RÉSumé}

Perception et pratique de la prophylaxie du paludisme pendant la grossesse chez les dispensateurs des soins de santé à Ibadan L'étude a évalué la connaissance et la pratique chez les dispensateurs de soins de santé à l'égard de concepts courants à l'égard de la prophylaxie du paludisme pendant la grossesse. Nous avons selectionné au hasard 497 répondants à tous les trois niveaux de soin dans deux administrations locales à Ibadan au sud-ouest du Nigéria qui ont été interviewés à l'aide d'un questionnaire auto-administré. Les répondants ont été selectionnés aupres des 45 établissements de santé: 48(9,7\%) parmi le personnel des services de santé extra-hospitalier (PSSEH) 139(28,9\%) infirmières auxillaires, $220(44,3 \%)$ infirmières formellement formées et $90(18,1 \%)$ médecins. Seuls $57(11,5 \%)$ des répondants connaissaient les stratégies courantes de l'OMS pour la prévention du paludisme pendant la grossesse. Trois cent quatre-vingt-six répondants $(77,7 \%)$ étaient au courant du traitement préventif intermittent (TPI). La conscience du TPI était la plus élevée parmi les PSSEH (95,8\%). Les dispensateurs de soins de santé ont surtout prescrit pyriméthamine au niveau secondaire (60, 6\%) et au niveau primaire $(60,3 \%)$ de soin $\left(X^{2}=11,54, \mathrm{p}<0,01\right)$. Chloroquine a été prescrite par $42,5 \%$ des répondants. Sulfadoxinepyriméthamine a été, de manière signifactive, la plus communément prescrite par les dispensateurs des services de soins primaries qu'à d'autres niveaux de soin $\left(\mathrm{X}^{2}=15,07, \mathrm{p}<0,01\right)$. La prescription pour les moustiquaires traités à l'insectide était considérable. La pratique de la chemoprophylaxie antipaludisme a été influencée par le cadre du dispensateur de soin de la santé et le niveau de la pratique. Il y a beaucoup de vide quant aux stratégies actuelles de la prévention du paludisme pendant la grossesse parmi les dispensateurs de soin de la santé. Il faut de multiples stratégies pour améliorer la connaissance et la pratique de la prévention du paludisme pendant la grossesse chez les dispensateurs de soin de la santé. (Rev Afr Santé Reprod 2007; 11[2]:60-69).

KEY WORDS: malaria in pregnancy, intermittent preventive treatment, malaria control, health care providers

Department of Obstetrics \& Gynaecology, University College Hospital, Ibadan

Corresponding Author: Dr. Fawole AO, Department of Obstetrics \& Gynaecology, University College Hospital, Ibadan Email:fawoleo@yahoo.co.uk 


\section{Introduction}

Malaria is a major public health problem, with the largest population at risk in sub-Saharan Africa. At least 300 million people become acutely ill with malaria each year, and more than a million die from the infection ${ }^{1}$. Over $80 \%$ of malaria deaths occur in Africa ${ }^{2}$. Malaria costs Africa an estimated 12 billion US dollars in lost production yearly ${ }^{2}$.

Pregnant women and their unborn babies are especially vulnerable to malaria. Each year, more than 25 million African women in malariaendemic areas become pregnant and are at risk of infection with Plasmodium falciparum ${ }^{2,3}$. Infection with Plasmodium falciparum during pregnancy increases the risk of maternal anaemia, spontaneous abortion, stillbirth, low birth weight and neonatal death, and is thought to be responsible for the death of approximately 10,000 African women and 200,000 infants each year.

The World Health Organization (WHO) recommends a package of interventions for the prevention and control of malaria during pregnancy. This comprises of intermittent preventive treatment (IPT), use of insecticide treated nets (ITNs), and access to effective case management for malaria illness and anaemia ${ }^{3}$. Routine prophylaxis for malaria during pregnancy is associated with reduced incidence of severe antenatal anaemia, higher birth-weight and fewer perinatal deaths 5 . ITNs have been shown to have beneficial impact on pregnancy outcome in malaria-endemic regions of Africa when used by communities or individual women ${ }^{6}$.

Presently, sulfadoxine-pyrimethamine (SP) is the only antimalarial medicine for which data on efficacy and safety for IPT is available from controlled clinical trials, and WHO recommends that at least 2 doses of SP are given after quickening during the second and third trimesters, at least one month apart. However even a single dose has been shown to be beneficial ${ }^{7}$.
One of the major challenges facing the implementation of malaria prevention strategies in pregnancy is creating awareness among healthcare providers ${ }^{8}$. A recent evaluation of the malaria prevention strategies using drugs among Nigerian obstetricians revealed that the majority were deficient in current evidence-based recommendations.' A policy document has been produced by the Nigerian health authority to guide health care workers on strategies for the prevention and control of malaria during pregnancy ${ }^{10}$. Therapeutic regimes used by healthcare workers are usually not in compliance with such guidelines as shown in the Republic of Benin where physicians and health care workers were unaware of their national policies for the control of malaria ${ }^{11}$.

Thus there appears to be a poor knowledge base regarding current evidence-based guidelines on malaria control during pregnancy among health care workers. Yet healthcare workers are crucial to effective malaria control. Therefore it is necessary to investigate their knowledge base on this crucial issue. Thus this study was designed to assess the knowledge of health care providers in Ibadan, south-western Nigeria on current concepts on malaria prophylaxis in pregnancy, to ascertain their preferred drugs and to identify strategies that would enhance programmes for preventing malaria during pregnancy.

\section{Methods}

This cross sectional descriptive study was conducted in Ibadan, Oyo state of south-western Nigeria between June and August 2006. Two of the five local government areas (LGAs) within Ibadan municipality were selected by random sampling. The selected LGAs were Ibadan North and Ibadan North East respectively. In each local government area, two public primary health facilities and a secondary health facility and at least $25 \%$ of all registered private health facilities were randomly selected from a list of all registered 
health facilities obtained from the Oyo state ministry of health.

Within Ibadan North LG, there were 10 public primary health facilities, one public secondary facility and a tertiary health facility. There were 115 registered private hospitals, clinics and maternity centre within the local government. In Ibadan North East local government, there were 13 public primary health facilities, 2 public secondary health facilities and 14 registered private hospitals, clinics and maternity centres. The only tertiary health care facility in Ibadan located within Ibadan North local government was selected.

The main study population consisted of all health care personnel who provide antenatal services in the selected health facilities. These included community health extension workers (CHEWs), auxiliary nurses, formally trained nurses and medical doctors. CHEWs are individuals with minimal education who have received some basic formal training; they are employed in primary health centres and provide maternity care. Auxiliary nurses are individuals with minimal education who are employed in private health facilities. They are given on-the-job training by individual Physicians; they also provide maternity care. Auxiliary nurses do not have formal training prior to employment. At the primary level of care in public health facilities, the health care personnel include CHEWs, trained nurses and midwives and a few Physicians. Auxiliary nurses, CHEWs, trained nurses and midwives and Physicians are the personnel in private health facilities. There are only trained nurses and midwives and Physicians in public secondary and tertiary health facilities.

A pre-designed semi-structured selfadministered questionnaire was given to randomly selected healthcare workers representing all cadres of healthcare workers who managed pregnant women in the different levels of healthcare. The questionnaire explored the respondents' knowledge of the hazards posed by malaria to pregnancy, current strategies for preventing it and their current practice regarding prophylaxis for malaria among pregnant women. It was pretested and the questions validated prior to commencement of the study.

Ethical approval was obtained from the Joint University of Ibadan/University College Hospital institutional review board. Approval for the study was also sought from the authorities of all selected health facilities. A trained research assistant distributed the questionnaires and recruited participants for the study. Each participant signed a written consent form after being given adequate explanation about the purpose of the study. Completed questionnaires were cleaned and edited prior to data entry.

Data entry and analysis were performed using the EPI-Info 6 statistical package from the US Centers of Disease Control and Prevention. The chi-square test was used to test for associations and the level of statistical significance was set at $\mathrm{p}<0.05$.

\section{Results}

A total of 551 questionnaires were administered; of these 501 were retrieved and 497 were sufficiently completed to permit detailed analysis. They were administered in 45 randomly selected health facilities in Ibadan North and Ibadan North East local government areas of Ibadan. The distribution of the un-completed questionnaires cut across the different levels of care and private and public health facilities. No refusals were reported.

Of these 45 health facilities, one was a tertiary healthcare facility and two were secondary healthcare facilities; one public and the other a missionary hospital. Of the remaining forty-two primary healthcare facilities, five were public health facilities and 37 were privately owned.

Two hundred and ninety six respondents $(59.6 \%)$ were in Ibadan North LGA while the remaining 201 respondents $(40.4 \%)$ were in Ibadan North-East LGA. Overall, 287 (57.8\%) respondents were in primary, $109(21.9 \%)$ were

African Journal of Reproductive Health Vol. 11 No.2 August 2007 
based in secondary and the remaining $101(20.3 \%)$ were found in the only tertiary healthcare facility.

Forty-eight respondents $(9.7 \%)$ were community health extension workers (CHEWS), 139 respondents $(28.9 \%)$ were auxiliary nurses. Formally trained nurses comprised 220 respondents $(44.3 \%)$ while the remaining 90 respondents $(18.1 \%)$ were medical doctors.

The majority of respondents $(94.6 \%)$ felt that training on malaria control should be institutionalized. Most respondents (90.3\%) felt the Federal government should subsidize antimalarial interventions.

Knowledge of WHO strategies on malaria prevention in pregnancy was poor with 57 respondents $(11.5 \%)$ having correct knowledge of all WHO strategies. Table 1 depicts knowledge of all WHO recommended strategies by professional cadre and levels of healthcare. A total of 386 respondents $(77.7 \%)$ were aware of intermittent preventive treatment. Awareness was highest among CHEWS (95.8\%). Though 349 respondents $(70.2 \%)$ believed IPT to be effective, 93 respondents $(18.7 \%)$ felt a single dose could be beneficial.
Knowledge among professional cadres and levels of healthcare practice of the correct drug, dose and timing of IPT is depicted in Table 2. CHEWs were more likely than other cadres of healthcare workers to correctly indicate the correct dose and timing of IPT $\left(\mathrm{X}^{2}=19.58, \mathrm{p}<0.01\right)$; respondents at the primary level of care were also more likely to report the correct dose and timing of IPT $\left(\mathrm{X}^{2}=25.40, \mathrm{p}<0.0001\right)$.

Sulfadoxine-pyrimethamine was the most widely prescribed antimalarial for prophylaxis with 335 respondents $(67.4 \%)$ prescribing it. Its use was highest among CHEWS (77.1\%) followed by auxiliary nurses $(73.4 \%)$ and medical doctors $(64.4 \%)$. It was least prescribed by trained nurses/midwives $(62.7 \%)$. These differences however did not reach statistical significance $\left(\mathrm{X}^{2}=6.86, \mathrm{p}>0.05\right)$.

Healthcare providers at the primary level of care were significantly more likely to use sulfadoxine-pyrimethamine for IPT than other levels of care, followed by tertiary healthcare providers $(65.4 \%)$. SP was least used by secondary healthcare providers $(53.2 \%)$. These differences were statistically significant $\left(\mathrm{X}^{2}=15.07, \mathrm{p}<0.01\right)$.

Table 1: Correct knowledge of WHO strategies for prevention of malaria in pregnancy by professional cadre and level of practice

\begin{tabular}{|l|l|l|l|}
\hline & Frequency & Total & Percentage (\%) \\
\hline Professional Cadre & \multicolumn{1}{|l|}{} \\
\hline CHEW & 8 & 48 & 16.7 \\
\hline Auxiliary Nurse & 17 & 139 & 12.2 \\
\hline Trained Nurse/Midwife & 16 & 220 & 7.3 \\
\hline Doctors & 16 & 90 & 17.8 \\
\hline Total & 57 & 497 & 11.5 \\
\hline \multicolumn{3}{|l|}{$\mathbf{X}^{\mathbf{2}}=\mathbf{8 . 7 0 ,}, \boldsymbol{p}=\mathbf{0 . 0 3}$} & \\
\hline Levels of Healthcare Practice & \multicolumn{1}{|l}{} \\
\hline Primary & 40 & 287 & 13.9 \\
\hline Secondary & 6 & 109 & 5.5 \\
\hline Tertiary & 11 & 101 & 10.9 \\
\hline Total & 57 & 497 & 11.5 \\
\hline & $X^{2}=5.60, p=0.06$ & \\
\hline
\end{tabular}

African Journal of Reproductive Health Vol. 11 No.2 August, 2007 
Table 2: Knowledge of the Correct Dose and Timing of IPT

\begin{tabular}{|l|l|l|l|}
\hline & Frequency & Total & Percentage (\%) \\
\hline Professional Cadre & \multicolumn{1}{|c|}{} \\
\hline CHEW & 31 & 48 & 64.6 \\
\hline Auxiliary Nurse & 65 & 139 & 46.8 \\
\hline Trained Nurse/Midwife & 92 & 220 & 41.8 \\
\hline Doctors & 51 & 90 & 56.7 \\
\hline Total & 239 & 497 & 48.1 \\
\hline \multicolumn{3}{|l|}{} \\
\hline Levels of Healthcare Practice & $\boldsymbol{X}^{2}=\mathbf{1 9 . 5 8 , \boldsymbol { p } < \boldsymbol { 0 . 0 1 }}$ & \\
\hline Primary & 156 & 287 & 54.4 \\
\hline Secondary & 36 & 109 & 33.0 \\
\hline Tertiary & 47 & 101 & 46.5 \\
\hline Total & 239 & 497 & 48.1 \\
\hline & $\boldsymbol{X}^{\mathbf{2}=\mathbf{2 5 . 4 0 ,} \boldsymbol{p}<\mathbf{0 . 0 0 0 1}}$ \\
\hline
\end{tabular}

The prescription for use of insecticide treated nets was generally high with $75.1 \%$ of respondents prescribing it. It was most prescribed by trained nurses/midwives $(80.0 \%)$ followed by auxiliary nurses $(79.9 \%)$ and CHEWs' $(72.9 \%)$. It was least prescribed by doctors $(56.67 \%)$; these differences were statistically significant $\left(\mathrm{X}^{2}=20.95, \mathrm{p}<0.001\right)$.

Two hundred and eleven respondents (42.5\%) prescribed Chloroquine (CQ) as antimalarial prophylaxis in pregnancy. CQ was most prescribed by CHEWs' (54.2\%) followed by auxiliary nurses $(48.9 \%)$ and trained nurses/ midwives (44.6\%). CQ was least prescribed by Medical Doctors (21.11\%) and the differences were statistically significant $\left(\mathrm{X}^{2}=22.25, \mathrm{p}<\right.$ 0.0001).

Chloroquine for antimalarial prophylaxis was more frequently prescribed by primary healthcare providers (49.8\%), followed by secondary healthcare providers $(36.7 \%)$; only $27.7 \%$ of tertiary healthcare providers prescribed it $\left(\mathrm{X}^{2}=16.83, \mathrm{p}<0.001\right)$.

Proguanil was prescribed by 191 respondents $(38.43 \%)$. Its prescription was highest among medical doctors (55 respondents, 61.1\%), followed by trained nurses/midwives (93 respondents, 42.3\%) and auxiliary nurses (35 respondents, $25.2 \%)$. It was least prescribed by CHEWS (8 respondents, $16.7 \%$ ). The differences in these prescription patterns attained statistical significance $(p<0.0001)$. By level of healthcare, tertiary healthcare providers prescribed it most (82 respondents, $81.2 \%$ ) followed by secondary health care providers (35 respondents, 32.1\%) while 74 primary healthcare providers $(25.8 \%)$ prescribed it $(\mathrm{p}<0.0001)$.

Two hundred and eighty-one respondents $(56.5 \%)$ prescribed pyrimethamine for antimalarial prophylaxis. It was mostly prescribed by auxiliary nurses (98 respondents, 70.5\%), followed by trained nurses/midwives (123 respondents, 55.9\%) and CHEWs' (23 respondents, $47.9 \%)$. It was least prescribed by medical doctors (37 respondents, 41.1\%). The differences reached statistical significance $\left(\mathrm{X}^{2}=\right.$ 21.24, $\mathrm{p}<0.0001)$.

Pyrimethamine was mostly prescribed by secondary healthcare providers (66 respondents, $60.6 \%)$ and primary healthcare providers (173 respondents, $60.3 \%$ ). It was least prescribed by

African Journal of Reproductive Health Vol. 11 No.2 August 2007 
tertiary healthcare providers (42 respondents, $41.6 \%$ ). These differences also reached statistical significance $\left(\mathrm{X}^{2}=11.54, \mathrm{p}<0.01\right)$.

CHEWs were least likely to correctly identify groups of pregnant women that required IPT as shown in Table 3. The majority of respondents from primary and secondary levels of care could not correctly indicate groups of pregnant women at higher risk of the effects of malaria (Table 4).

\section{Discussion}

Provision of care conforming to standard guidelines is one of the major elements of quality of care $^{12}$. Consequently, periodic assessment of practice will yield valuable insights regarding the quality of care given to pregnant women. Such an endeavour is particularly relevant in the control of malaria during pregnancy from the public health perspective.

Current strategies for malaria control in pregnancy are based on the tripod of IPT, vector control and prompt treatment of acute illness. The performance of any health system with regards to control of malaria and thereby reduction of malaria related morbidity and mortality can thus be evaluated by the extent to which it meets these best practices.

This study revealed a poor knowledge of WHO strategies against malaria in pregnancy among healthcare providers; only one-tenth were

\section{Table 3: Knowledge of Antimalarial Prophylaxis under Special Circumstances in Pregnancy} by Professional Cadre

\begin{tabular}{|c|c|c|}
\hline Professional Cadre & Frequency & Percentage $(\%)$ \\
\hline \multicolumn{3}{|c|}{ First \& Second Pregnancies } \\
\hline CHEW & 13 & 27.1 \\
\hline Auxiliary Nurse & 44 & 31.7 \\
\hline Trained Nurse/Midwife & 83 & 37.7 \\
\hline Doctors & 47 & 52.2 \\
\hline Total & 187 & 37.6 \\
\hline \multicolumn{3}{|c|}{$X^{2}=12.56, p<0.01$} \\
\hline \multicolumn{3}{|c|}{ Patients with Haemoglobinopathies } \\
\hline CHEW & 17 & 35.4 \\
\hline Auxiliary Nurse & 66 & 47.5 \\
\hline Trained Nurse/Midwife & 103 & 46.8 \\
\hline Doctors & 63 & 70.0 \\
\hline Total & 249 & 50.1 \\
\hline \multicolumn{3}{|c|}{$X^{2}=19.72, p<0.001$} \\
\hline \multicolumn{3}{|l|}{ HIV Positive Patients } \\
\hline CHEW & 7 & 14.6 \\
\hline Auxiliary Nurse & 40 & 28.8 \\
\hline Trained Nurse/Midwife & 92 & 41.8 \\
\hline Doctors & 52 & 57.8 \\
\hline Total & 191 & 38.4 \\
\hline \multicolumn{3}{|c|}{$X^{2}=32.31, p<0.001$} \\
\hline
\end{tabular}

African Journal of Reproductive Health Vol. 11 No.2 August, 2007 
Table 4: Knowledge of Indications for Antimalarial Prophylaxis under special Circumstances in Pregnancy by level of Practice

\begin{tabular}{|c|c|c|}
\hline Level of Healthcare & Frequency & Percentage $(\%)$ \\
\hline \multicolumn{3}{|c|}{ First \& Second Pregnancies } \\
\hline Primary & 84 & 29.3 \\
\hline Secondary & 35 & 32.1 \\
\hline Tertiary & 68 & 67.3 \\
\hline Total & 187 & 37.6 \\
\hline \multicolumn{3}{|c|}{$X^{2}=47.92, p<0.0001$} \\
\hline \multicolumn{3}{|c|}{ Patients with Haemoglobinopathies } \\
\hline Primary & 122 & 42.5 \\
\hline Secondary & 43 & 39.5 \\
\hline Tertiary & 84 & 83.2 \\
\hline Total & 249 & 50.1 \\
\hline \multicolumn{3}{|c|}{$X^{2}=55.74, p<0.0001$} \\
\hline \multicolumn{3}{|l|}{ HIV Positive Patients } \\
\hline Primary & 75 & 26.1 \\
\hline Secondary & 38 & 34.9 \\
\hline Tertiary & 78 & 77.2 \\
\hline \multirow[t]{2}{*}{ Total } & 191 & 38.4 \\
\hline & $X^{2}=83.18, p<0.0001$ & \\
\hline
\end{tabular}

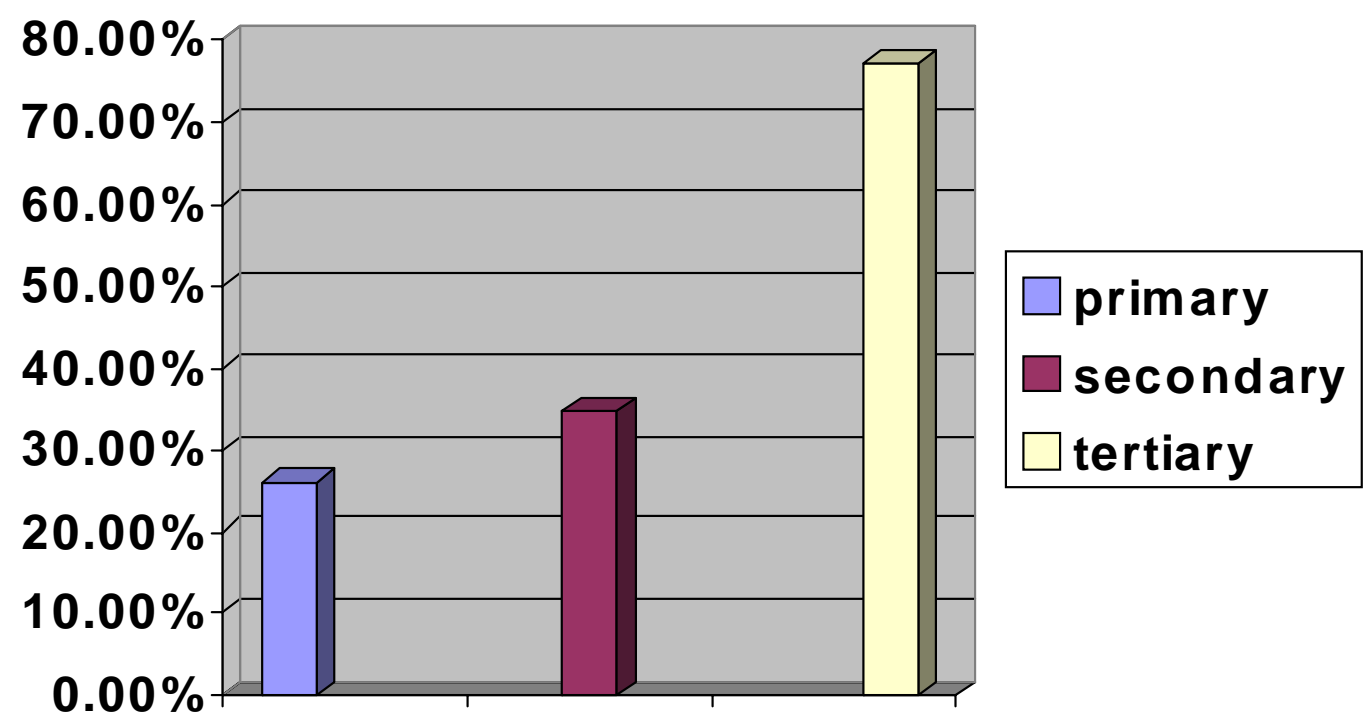


aware of the correct WHO strategies. This poor knowledge was evident among all cadres and levels of healthcare providers.

Approximately three-quarters of respondents were aware of intermittent preventive treatment. Sulfadoxine-pyrimethamine (SP) was the most widely prescribed antimalarial for prophylaxis with approximately two-thirds of respondents prescribing it in pregnancy. This was not surprising as its low cost, wide availability, easy deliverability and acceptability make it the clear choice in countries where efficacy of the drug remains $\operatorname{good}^{13}$.

However, further assessment of the awareness revealed surprising knowledge gaps. Only half of respondents knew the correct dose and timing of IPT. This was dependent on both professional cadre and level of healthcare with the CHEWs' and primary healthcare providers being most knowledgeable. This could be due to the fact that WHO efforts are focused on developing primary healthcare practice in the developing world, so these groups are better educated and informed about current WHO strategies.

Three-quarters of respondents prescribed insecticide treated nets (ITNs) for use. As heartwarming as this might be, it is important to note that prescription for use does not necessarily lead to similar coverage results. Attributable reasons for the difference include cost of ITNs' which is a barrier to their widespread use and the erroneous perception in some areas that chemicals for treatment of nets could be harmful ${ }^{14}$. The disheartening and alarming news is that approximately half of our doctors do not counsel patients on the use of ITNs' which has been shown to be effective.

Approximately two-fifths and three-fifths of healthcare providers still prescribe chloroquine and pyrimethamine respectively despite overwhelming evidence against such practice due to increasing resistance to these drugs, and reducing efficacy of chloroquine (CQ) chemoprophylaxis ${ }^{15}$ and weekly pyrimethamine ${ }^{16,17}$. The possible reasons for this would include easy availability, affordability. Another important but often overlooked reason could be the inefficient dissemination of current information to healthcare providers leading to ignorance and poor knowledge of drug resistance patterns and efficacy.

Assessment among respondents of knowledge of the groups of pregnant women that need antimalarial prophylaxis again showed several knowledge gaps. Only about two-fifths of all respondents agreed to use of malaria prophylaxis for first and second pregnancies and HIV patients, while only half felt use of prophylaxis for sickle cell disease patients was appropriate. This is disappointing as it is known that the deleterious impact of malaria is particularly more in first and second pregnancies ${ }^{18}$. Additionally women with HIV infection are more likely to have symptomatic malaria infections and to have an increased risk of an adverse birth outcome due to malaria ${ }^{3}$. Anti-malarial prophylaxis in this group is justified given the association of placental parasitaemia with increased risk of vertical transmission of HIV ${ }^{19,20}$. The WHO therefore recommends three IPT doses for HIV positive women ${ }^{3}$. IPT is also recommended for patients with sickle cell disease as this reduces the possibility of sickle cell crisis due to malaria infections ${ }^{21}$.

\section{Conclusion and Recommendations}

This study has highlighted several knowledge gaps on current malaria prevention strategies in pregnancy among healthcare providers. Lack of awareness is apparently the major obstacle to changing practice ${ }^{8}$; incorporating new strategies into routine antenatal care programmes will therefore require active dissemination of this information among the various cadres of health workers providing antenatal care.

Possible solutions include institutionalizing malaria prevention strategies in pregnancy ${ }^{22}$ and continuing professional development programmes 
on current concepts by healthcare providers. Professional associations by their strategic positions should indeed take the lead in this area. Some researchers have advocated the creation of an organization to promote consultation and communication between health care authorities and workers ${ }^{11}$.

\section{Acknowledgements}

We acknowledge the co-operation of the staff of Obstetrics and Gynaecology departments of the University College Hospital, Ibadan, Catholic Hospital, Oluyoro, Ibadan, and Adeoyo Maternity Hospital, Ibadan. The contribution of the research assistants and all the participants in this study is gratefully acknowledged.

\section{REFERENCES}

1. WHO. Roll Back Malaria (RBM) 2002; Info-sheet 3 of 11 .

2. WHO. Malaria and HIV interactions and their implications for public health policy. Report of a technical consultation, Geneva, 2004.

3. WHO. A Strategic Framework for Malaria Prevention and Control during Pregnancy in the African Region. Brazzaville: World Health Organization Regional Office for Africa, 2004.

4. Steketee RW, Nahlen BL, Parise ME, Menendez C. The burden of malaria in pregnancy in malariaendemic areas. Am J Trop Med Hyg 2001; 64 (1-2 Suppl):28-35.

5. Garner P, Gulmezoglu AM. Drugs for preventing malaria related illness in pregnant women and death in the newborn. The Cochrane database of systematic reviews 2002, issue 4.

6. Gamble C, Ekwaru JP, ter Kuile FO: Insecticide treated nets for preventing malaria in pregnancy. The Cochrane database of systematic reviews 2006, issue 2 .

7. Shulman CE, Dorman EK, Cutts F, Kawuondo K, Bulmer JN, Peshu N, Marsh K. Intermittent sulphadoxine-pyrimethamine to prevent severe anaemia secondary to malaria in pregnancy: a randomised placebo-controlled trial. 1999; 353(9153):632-6.
8. Fawole B. Drugs for preventing malaria related illness in pregnant women and death in the newborn: RHL commentary. The WHO Reproductive Health Library, No 7, Update software Ltd, Oxford. 2004.

9. Onah HE, Nkwo PO, Nwankwo TO. Malaria chemoprophylaxis during pregnancy: A survey of current practice amongst Nigerian Obstetricians. Trop. J Obstet Gynaecol. 2006; 23 (1) 17-19.

10. Federal Ministry of Health. National Guidelines and Strategies for Prevention and Control of malaria during Pregnancy. Abuja, Federal Government of Nigeria, May 2005.

11. Nahum A, Akogbeto M Malaria and pregnancy: attitude of health care personnel during prenatal care in Cotonou, Benin Med Trop (Mars). 2000; 60(3):251-5.

12. O'Connor PJ. Adding value to evidence-based clinical guidelines. JAMA 2005; 294 (6): 741 - 743.

13. Newman RD, Parise ME, Slutsker L, Nahlen B, Steketee W. Safety, efficacy and determinants of effectiveness of antimalarial drugs during pregnancy: implications for prevention programmes in Plasmodium falciparum-endemic sub-Saharan Africa. Trop Med Int Health. 2003; 8(6):488-506.

14. Mbonye AK, Neema S, Magnussen P. Preventing malaria in pregnancy: a study of perceptions and policy implications in Mukono district, Uganda. Health Policy Plan. 2006; 21(1):17-26.

15. Kayentao K, Kodio M, Newman RD, Maiga H, Doumtabe D, Ongoiba A, Coulibaly D, Keita AS, Maiga B, Mungai M, Parise ME, Doumbo O. Comparison of intermittent preventive treatment with chemoprophylaxis for the prevention of malaria during pregnancy in Mali. J Infect Dis. 2005; 191(1):109-16.

16. Nahlen BL, Akintunde A, Alakija T, Nguyen-Dinh P, Ogunbode O, Edungbola L D, Adetoro O, Breman JG Lack of efficacy of pyrimethamine prophylaxis in pregnant Nigerian women. Lancet. 1989; 2(8667):830-4.

17. Akindele JA, Sowunmi A, Abohweyere AE. Congenital malaria in a hyperendemic area: a preliminary study. Ann Trop Paediatr. 1993; 13(3):273-6.

African Journal of Reproductive Health Vol. 11 No.2 August 2007 
Perception and Practice of Malaria Prophylaxis in Pregnancy among Health care Providers in Ibadan 69

18. Rogerson SJ, Chaluluka E, Kanjala M, Mkundika $\mathrm{P}$, Mhango C, Molyneux ME. Intermittent sulfadoxine-pyrimethamine in pregnancy: effectiveness against malaria morbidity in Blantyre, Malawi, in 1997-99. Trans R Soc Trop Med Hyg. 2000; 94(5):549-53.

19. Ayisi JG, Van Eijk M, Newman RD, ter Kuile FO, Slin Y, Yang C, Kolezak MS, Otieno JA, Misore AO, Kager PA, Lal RB, Steketee RW, Nahlen BL. Maternal malaria and perinatal HIV transmission, Western Kenya. Emerg Infect Dis. 2004; 10(4): 64352.
20. Brahmbhatt H, Kigozi G, Wabwire-Mangen F, Serwadda D, Sewankambo N, Lutalo T, Wawer MJ, Abramowsky C, Sullivan D, Gray R. The effects of placental malaria on mother to child HIV transmission in Rakai, Uganda. AIDS. 2003; 17(17): 2539-41.

21. Federal Ministry of Health, Nigeria. Rational use of antimalarial drugs. In: National antimalarial treatment policy. National malaria and vector control Division, Abuja. Nigeria. 2005; 27-32.

22. Jasper N, Ijumba J, Andrew Y, Kitua AY. Enhancing the application of effective malaria interventions in Africa through training. Am. J. Trop. Med. Hyg., 2004; 71(Suppl 2), 253-258. 